\title{
Comparing two basic subtypes in OCD across three large community samples: a pure compulsive versus a mixed obsessive- compulsive subtype
}

\author{
Stephanie Rodgers ${ }^{1}$ - Vladeta Ajdacic-Gross ${ }^{1}$ - Wolfram Kawohl ${ }^{1,2} \cdot$ Mario Müller $^{1}$. \\ Wulf Rössler ${ }^{1,3,4} \cdot$ Michael P. Hengartner $^{5} \cdot$ Enrique Castelao $^{6} \cdot$ Caroline Vandeleur $^{6}$. \\ Jules Angst ${ }^{1} \cdot$ Martin Preisig $^{6}$
}

Received: 9 October 2014 / Accepted: 15 March 2015 / Published online: 1 April 2015

(C) Springer-Verlag Berlin Heidelberg 2015

\begin{abstract}
Due to its heterogeneous phenomenology, obsessive-compulsive disorder (OCD) has been subtyped. However, these subtypes are not mutually exclusive. This study presents an alternative subtyping approach by deriving non-overlapping OCD subtypes. A pure compulsive and a mixed obsessive-compulsive subtype (including subjects manifesting obsessions with/without compulsions) were analyzed with respect to a broad pattern of psychosocial risk factors and comorbid syndromes/diagnoses in three representative Swiss community samples: the Zurich Study $(n=591)$, the ZInEP sample $(n=1500)$, and the PsyCoLaus sample $(n=3720)$. A selection of comorbidities was examined in a pooled database. Odds ratios were derived from logistic regressions and, in the analysis of pooled data, multilevel models. The pure compulsive subtype showed a lower age of onset and was characterized by few associations with psychosocial risk factors. The higher social popularity of the pure compulsive subjects and their families was remarkable. Comorbidities within
\end{abstract}

Stephanie Rodgers

stephanie.rodgers@dgsp.uzh.ch

1 Department of Psychiatry, Psychotherapy and Psychosomatics, Psychiatric Hospital, University of Zurich, PO Box 1930, 8021 Zurich, Switzerland

2 University of Zurich, Zurich, Switzerland

3 Collegium Helveticum, University of Zurich and Swiss Federal Institute of Technology, Zurich, Switzerland

4 Laboratory of Neuroscience (LIM 27), Institute of Psychiatry, University of Sao Paulo, São Paulo, Brazil

5 Department of Applied Psychology, Zurich University of Applied Sciences, Zurich, Switzerland

6 Department of Psychiatry, Lausanne University Hospital, Lausanne, Switzerland the pure compulsive subtype were mainly restricted to phobias. In contrast, the mixed obsessive-compulsive subtype had a higher prevalence and was associated with various childhood adversities, more familial burden, and numerous comorbid disorders, including disorders characterized by high impulsivity. The current comparison study across three representative community surveys presented two basic, distinct OCD subtypes associated with differing psychosocial impairment. Such highly specific subtypes offer the opportunity to learn about pathophysiological mechanisms specifically involved in OCD.

Keywords Obsessive-compulsive disorder - Distinct subtypes $\cdot$ Comorbidity $\cdot$ Epidemiology

\section{Introduction}

Since the first description of obsessive-compulsive disorder (OCD), clinicians have described it as a phenotypically heterogeneous condition. As early as 1866, Falret [22] distinguished between folie du doute (madness of doubt) and délire du toucher (delusion of touch) [30, 38]. Obsessions are unwanted thoughts, images, or urges leading to subjective distress. Compulsions are repetitive behaviors or mental acts that the subject feels obliged to perform [64]. Despite its obvious heterogeneity comprising thoughts and behaviors, standard classification systems- the DSM-5 and the ICD-10—classify OCD as a unitary entity [14, 38]. As a consequence, the heterogeneity of OCD can reduce the power of and obscure findings from clinical trials, neuroimaging studies, and gene localization methods [39]. Researchers have attempted to cope with this heterogeneity by identifying OCD subgroups which can be classified on the basis of symptom-specific clusters, socio-demographic 
(age of onset), genetic, and phenomenological data, comorbid tic disorders (including Tourette's syndrome), neurophysiological techniques, or clinical characteristics (course, positive family history of OCD) $[38,51]$. A further strategy for deriving useful OCD subtypes was developed by broadening the diagnostic boundaries and searching for OCD spectrum disorders that might share common underlying mechanisms/etiologies. Studies in this area have yielded relations with tic disorders, depressive and anxiety disorders, trichotillomania, skin picking, grooming behaviors, body dysmorphic disorder, and idiopathic focal dystonia [42].

Existing studies aimed at identifying symptom-specific subtypes have often used data reduction methods such as variable-centered factor analysis, person-centered cluster analysis, or latent class analysis (LCA) [19, 40]. MataixCols et al. $[38,39]$ reviewed the investigative literature on this topic and found strong evidence for the following four symptom dimensions: contamination/washing, hoarding, symmetry/ordering, and aggressive/checking. Some studies identified a further dimension that included pure obsessions, e.g., patients having unacceptable/taboo thoughts without compulsions $[1,34,68]$. However, the symptom-specific subtypes are not mutually exclusive and each patient can simultaneously score on more than one symptom dimension [39]. In more technical terms, differentiation between subtypes was performed overlapping. In contrast, a distinctive subtyping approach classifies subjects into mutually exclusive, pure categories. The differentiation of unipolar and bipolar disorders is an example of such a distinctive classification or operational definition. Last but not least, attention-deficit hyperactivity disorder (ADHD) provides an intermediate variant: subtypes with prevailing main characteristics. Critically speaking, the operational definitions of subtypes of mental disorders are based on gradual development and not on systematic reflection. There are two paths to keep on asking. Firstly, a nosological path: Which operational definition is the most appropriate for a specific disorder in substantial terms - an overlapping, a distinctive, or an intermediate one? And secondly, a methodological path: Can we derive more specific information about a disorder, for example, regarding pathophysiological mechanisms, from more specific subtypes? In some instances, the second, i.e., methodological path focusing on extreme subtypes is useful for strategical reasons, regardless of nosological ambiguities.

In this study, we explored the distinctive subtyping approach to OCD symptom-specific subtypes. The most basic differentiation in OCD is that between compulsions and obsessions. Hypothetically, both compulsions and obsessions can persist as singular phenomena or they can overlap as a mixed type. However, preliminary analyses of data from the longitudinal Zurich Study [6, 9] showed that pure obsessions tended to disappear over time, and, if they continued, mostly co-occurred with compulsions (data not shown). We decided not to include pure obsessions as a separate category considering the fact that temporal stability is an important validity criterion of a psychopathological construct [35], and moreover, converging evidence from cross-sectional and longitudinal studies indicates that the pure obsessive OCD subtype may be an invalid concept $[26,67,68]$. Furthermore, neurobiological models of obsessions are lacking [27]. In their currently published review, Gillan and Sahakian [27] suggested from a neurobiological perspective that compulsions may represent a core component of OCD and not, as traditionally assumed, merely a coping mechanism or an epiphenomenon. The authors encourage a rethinking of the conventional model assuming that OCD is driven by obsessions and instead suggest a backward-looking model: Perhaps compulsions are the core OCD feature and obsessions represent only a troublesome by-product [27]. Therefore, the current study focused on two distinct subgroups of persons meeting the diagnostic criteria of OCD: subjects endorsing pure compulsions and subjects endorsing mixed obsessive-compulsive symptoms (i.e., obsessions with/without compulsions). To date, no community study has looked at these two subtypes with regard to their association patterns with psychosocial risk factors or comorbid disorders. For these reasons, we investigated the association patterns of a pure compulsive subtype (PCS) and a mixed obsessive-compulsive subtype (MOCS) in comparison with unaffected subjects. Three large community surveys in Switzerland were used, of which one was designed longitudinally (Zurich Study) and two initially had a cross-sectional study design (ZInEP and PsyCoLaus).

\section{Materials and methods}

\section{Samples and measurement instruments}

The three epidemiological samples used in the current paper will be illustrated in the following sections. A major aim of all three studies was to record data on the prevalence of threshold and subthreshold psychopathological syndromes/disorders in the Swiss community of adults.

\section{The Zurich Study sample}

The prospective longitudinal Zurich Study $[6,9]$ is based on an initial screening procedure of a representative sample of adults, born in 1958 and 1959. For this initial step, the Symptom Checklist-90-R (SCL-90-R) [20] was used. The SCL-90-R screens for the subjective burden related 
to psychiatric and somatic symptoms occurring in the past 4 weeks. It consists of 90 items rated on a 5-point Likert scale ranging from "not at all" (1) at one pole to "a little bit" (2), "moderately" (3), "quite a bit" (4), and "extremely" (5). The following nine subscales can be derived from the items: somatization, obsessive-compulsive, interpersonal sensitivity, depression, anxiety, hostility, phobic anxiety, paranoid ideation, and psychoticism. Additionally, a Global Severity Index (GSI) can be computed [20]. Based on the 85th percentile of the GSI of the SCL-90-R, the initial screening sample was stratified into two-thirds of randomly selected high scorers and onethird of randomly drawn low scorers for the Zurich Study. This resulted in a sample of 591 subjects (299 females and 292 males) interviewed at seven time points from 1979 to 2008 (1979, 1981, 1986, 1988, 1993, 1999, 2008). From the original sample, 335 subjects $(57 \%)$ participated in the last follow-up in 2008. The detailed participation rates were $43 \%$ in all seven interviews; $13 \%$ in six interviews; $11 \%$ in five interviews; $9 \%$ in four interviews; $7 \%$ in three interviews; $9 \%$ in two interviews; and $9 \%$ in one interview. For more information with regard to methods, see Rössler et al. [58].

The Structured Psychopathological Interview and Rating of Social Consequences of Psychic Disturbances for Epidemiology (SPIKE) [6], the semi-structured main instrument in the Zurich Study, consists of a comprehensive battery of demographic, somatic, and psychiatric questions and enables the establishment of psychiatric diagnoses according to the version of the DSM criteria available at the time of interview. Each syndrome is screened with regard to its major phenomenological features. In case the screening probe is positively endorsed, specific symptoms, duration, frequency, severity, treatment history, and subjective impairment are assessed [9]. The inter-rater reliability and validity of the SPIKE have been successfully confirmed $[33,41]$.

In the current study, socio-demographics, familial psychopathology, and common mental disorders (CMD) were derived from the SPIKE. CMD were represented by cumulative prevalence rates. The psychosis syndromes were computed using the two subscales schizophrenia nuclear symptoms (SNS) and schizotypal signs (STS) [59] derived from the SCL-90-R [20] and dichotomized according to their longitudinal pattern (continuously high level vs. other). In order to obtain more valid results, analyses including the SNS and STS variables were restricted to a reduced sample, i.e., participants who completed at least five out of seven follow-up interviews. As described elsewhere [59], missing values were replaced by a missing value analysis using the expectation maximization (EM) algorithm. The Zurich Study was approved by the local ethics committee.

\section{The ZInEP epidemiology sample}

The ZInEP epidemiology survey is a subproject of the Zurich Program for Sustainable Development of Mental Health Services (ZInEP; German: Zürcher Impulsprogramm zur nachhaltigen Entwicklung der Psychiatrie). The epidemiology survey consists of four components: (1) a telephone screening, (2) a semi-structured interview supplemented by self-report questionnaires, (3) socio-physiological tests focusing on stress and psychotic symptoms, and (4) a longitudinal survey. The survey was carried out between 2010 and 2012. For the present article, data from the first two study parts were used, which are methodologically adapted from the Zurich Study [6, 9].

First, 9829 subjects representative of the canton of Zurich were screened by a computer-assisted telephone interview (CATI) using the SCL-27 [31], a shortened version of the SCL-90-R [20]. The SCL-27 contains six subscales covering current symptoms of depression, dysthymia, vegetative symptoms, agoraphobia, social phobia, and symptoms of mistrust. Like the SCL-90-R, the SCL-27 also yields a GSI. The records of the screening sample were randomly chosen from the communal public authority register. The sample was restricted to 20- to 41-year-old adults with Swiss nationality. In cases where the potential participant could be reached by telephone, the response rate was $73.9 \%$. The overall response rate was $53.6 \%$.

Second, 1500 participants from this initial screening sample were selected at random and interviewed in detail using a face-to-face interview. A stratified sample procedure was applied that included $60 \%$ high scorers and $40 \%$ low scorers (cutoff criterion 75th percentile of the GSI of the SCL-27 [31]) using a shortened version of the SPIKE (referred to as Mini-SPIKE) [6, 9]. The detailed modifications of the SPIKE were recently described in detail by Ajdacic-Gross et al. [2]. When asked for a face-to-face appointment, $64.9 \%$ actually showed up. Socio-demographic characteristics, CMD, familial burden, and questions concerning language (e.g., stuttering) were derived from the Mini-SPIKE.

CMD were computed as 12-month prevalence rates. Exceptions included the following diagnoses: generalized anxiety disorder (GAD) with a modified time criterion of 1 month; neurasthenia, which was based on ICD-10 criteria; agoraphobia where the criteria were adapted according to DSM-V with regard to number of symptoms and coding of impairment; and mania/hypomania and bipolar disorders which were adapted to the criteria of the Bridge Study [5]. The diagnosis of adult attention-deficit/hyperactivity disorder (ADHD) was derived from the ADHD SelfRating Scale [55]. Childhood ADHD was assessed with the Wender Utah Rating Scale (WURS-k) [53], retrospectively referring to the age range between 8 and 10 years. 
This scale is well validated in both males (sensitivity: $85 \%$; specificity: $76 \%[52,56]$ ) and females (sensitivity: $93 \%$; specificity: $92 \%$ [54]). In order to assess psychosis, SNS and STS scores were derived from the SCL-90-subscale $[20,59]$. These two psychosis scales have previously been assessed in independent community samples and populations [57, 60]. Finally, post-traumatic stress disorder (PTSD) was screened for using the short scale of Breslau and colleagues [15]. The sensitivity of this scale was $80 \%$, and the specificity was even $97 \%$ [15]. Child maltreatment was assessed using the German short form of the Childhood Trauma Questionnaire (CTQ) [12, 13, 70]. This instrument shows good validity and reliability $[11,13,70]$. Further childhood adversities were assessed in parallel with questions used in the Zurich Study.

The ZInEP study was approved by the Ethics Committee of the Canton of Zurich (KEK) and is in strict accordance with the Declaration of Helsinki of the World Medical Association. All participants gave their written consent.

\section{The PsyCoLaus sample}

The PsyCoLaus study [49] is the psychiatric branch of the population-based CoLaus study [25]. Participants of CoLaus $(n=5535)$ were randomly selected between 2003 and 2006 in the city of Lausanne [25, 45]. Apart from the collection of clinical data and blood samples, subjects were interviewed with a semi-structured questionnaire [45]. One year later, all participants of CoLaus aged from 35 to 66 years were invited to participate in PsyCoLaus, a substudy which employed a psychiatric diagnostic interview administered by trained psychologists. A total of 3720 individuals (67 \%) took part in PsyCoLaus [49].

The psychiatric part of the assessment within the PsyCoLaus study used the French version of the semi-structured Diagnostic Interview for Genetic Studies (DIGS) [46, 48]. The DIGS was developed by the NIMH Molecular Genetics Initiative in order to assess phenotypes more precisely through a broad spectrum of DSM-IV Axis I criteria, and extensive information on the course and chronology of comorbid features [49]. Similarly to the SPIKE, the DIGS chapters also begin with a screening question followed by more detailed questions, e.g., regarding current, past and most severe episode, occurring symptoms, treatment, and disability. Inter-rater and test-retest reliability of the French version of the DIGS were successfully established for major mood and psychotic disorders [48] as well as for substance use and antisocial personality disorders [10]. For the current study, socio-demographic characteristics, lifetime prevalence of CMD, language and learning problems, childhood adversities, and familial psychopathology were derived from the DIGS.
The study was approved by the Ethics Committee of the University of Lausanne. After being informed of the goal and funding of the study, all participants gave their written informed consent [49].

\section{Distinctive OCD subtype classification}

For subtype classification, information was derived from the semi-structured diagnostic interviews SPIKE (Zurich Study), Mini-SPIKE (ZInEP), and DIGS (PsyCoLaus). The first question of the OCD sections screened for the occurrence of OCD symptoms. In more detail, the screening question of the SPIKE was: "During the past 12 months, did you experience any compulsive thoughts, persistent ideas or repetitive actions, which you were forced to think, to consider or to carry out against your will, although you knew that there was no need for it? For example, checking things over and over again, incessant hand washing, obsessive counting, persistent melodies or thoughts?" [24]. The screening question of the Mini-SPIKE was equivalent, but the examples were extended as follows: "e.g., checking whether the light switch was turned off or the front door was locked although you knew that you had already done it; or spending time cleaning things repeatedly although you know that they are clean; or do you experience disagreeable and unwanted ideas and images against which you can't defend yourself?". The DIGS screened separately for (a) obsessions and (b) compulsions: (a) "Have you ever been bothered by thoughts that did not make any sense, that kept coming back to you even when you tried not to have them?" If unclear: "Did these thoughts continue to bother you no matter how hard you tried to get rid of them or ignore them?" (b) "Have you ever had to repeat some act over and over which you could not resist repeating in order to feel less anxious-like washing your hands, counting things, or checking things?"

If the screening question was affirmed, the question "Could you describe the manifestation more precisely?" assessed the specific OCD symptoms in the SPIKE. The earlier versions of the SPIKE specifically asked about the five to six domains compulsive checking, compulsive washing, obsessive thoughts, other compulsive acts, counting compulsions, and anxiety. Since 1993, the symptoms have been differentiated and extended, resulting in the following compulsive symptoms: compulsion to check things; exaggerated tidiness, repeated dusting of certain things; rigid schedules for doing everyday tasks; over cautiousness with regard to money; obsessive counting. Obsessive symptoms were assessed by the following items: excessive fear of getting dirty, of contamination, of illness; exaggerated guilt feelings about not fulfilling your duties; thoughts of inflicting harm upon yourself or members of your family; obsessive sexual thoughts and ideas [24]. The symptom list 
within the Mini-SPIKE was identical, apart from the following obsessive symptom: "Thoughts, words or images about injury or accidents involving oneself or another person.” Both the SPIKE and Mini-SPIKE provided the opportunity to assess further symptoms, which had not been captured by the above-mentioned items. Within the DIGS, an open question assessed the exact obsessive/compulsive symptoms.

First, subjects positively endorsing the screening questions and meeting the diagnostic criteria for OCD in DSM were separately selected in all three epidemiological samples. Within the SPIKE and Mini-SPIKE, the distinctive OCD subtypes were derived based on the information of the items assessing obsessive and/or compulsive symptoms. Within PsyCoLaus, the screening questions encompassing obsessions/compulsions were used. The differentiated assessment of obsessive and compulsive symptoms enabled the programming of distinctive, non-overlapping OCD subtypes. Depending on the respective occurrence of symptoms, distinctive OCD subtypes were computed as follows: Subjects belonging to the PCS were characterized by compulsive acts without obsessive thoughts; subjects with obsessive thoughts with/without compulsive acts were classified into the MOCS.

Differentiating the PCS according to the four established symptom clusters aggressive/checking, symmetry/ordering, contamination/washing, and hoarding [38] revealed that in the Zurich Study, all PCS subjects manifested checking symptoms over time. In the ZInEP sample, the majority of subjects $(81.8 \%)$ classified under PCS manifested symptoms of the checking cluster. But $26.9 \%$ of subjects with checking symptoms also showed symptoms from the clusters contamination/washing or symmetry/ordering. In the PsyCoLaus sample, there was a lower percentage of subjects in the checking/aggressive cluster (42\%), somewhat more in the domain contamination/washing (50\%), and $25 \%$ in the cluster symmetry/ordering. When symptoms occurred in more than one cluster $(17 \%)$, they occurred combined in the clusters contamination/washing and checking/aggressive. No information about hoarding symptoms was available.

\section{Statistical analysis}

Basic descriptive models and cross-tabulations were calculated. Bivariate logistic regression analyses [odds ratios (ORs) and confidence intervals (CI $95 \%$ )] were computed to assess the associations between the psychosocial factors/comorbidities (treated as independent variables) and the OCD subtypes and OCD overall diagnosis, respectively (treated as dependent variables). As an exception, ANOVAs were computed for the metric scaled variable age of onset. In the Zurich Study sample, the data of the low scorers were weighted by the factor 11.3 to offset stratification bias and to receive correct ORs and CI. This upweighted sample represented a total of 2600 subjects. In the ZInEP sample, the corresponding design weight was 4.5 leading to a sample of 3600 subjects. Additional weights were introduced to account for nonresponse/ underrepresentation according to urbanicity status, education level, and the weight of any specific sex-birth year subgroup within the population of the 20-40 years old. The sampling and weighting procedures were described in detail by Ajdacic-Gross et al. [2]. Additional analysis pooling all available individual data was performed in order to enlarge the statistical power of the findings derived from the three separate data sets. The Breslow-Day test was used for testing the homogeneity of ORs in order to examine the appropriateness of fixed versus random effect models. Overall ORs were estimated in the analysis of pooled data by both bivariate logistic regression analyses and multilevel analyses, applying two-level regression analyses with random intercepts.

Statistical analysis of stratified samples requires modeling procedures that take the strata and weightings into account. The analyses were carried out using SAS (version 9; Institute Inc, Cary, NC), IBM SPSS 20 (Corp. Armonk, NY, USA) for Macintosh, and Mplus version 7 [43] for Macintosh. In the analyses of stratified samples (Zurich Study and ZInEP), the SAS survey procedures SURVEYFREQ, SURVEYMEANS, and SURVEYLOGISTIC were used. Mplus was used for the analyses on the pooled data set. As an exception, the Breslow-Day test was computed based on the SAS procedure PROC FREQ. The preliminary significance level was set at $p<0.05$ for all tests.

\section{Results}

Table 1 illustrates the main socio-demographic characteristics of the three epidemiological samples.

Tables 2, 3, 4, 5, 6, 7, 8, and 9 display the results of the univariate and bivariate analyses for the Zurich Study sample (Tables 2, 3, 4), the ZInEP sample (Tables 5, 6, 7), and the PsyCoLaus sample (Tables 8, 9). In each table, the figures for the distinctive OCD subtypes (PCS and MOCS) are shown for a set of psychosocial variables and comorbid syndromes/diagnoses. For a general view, the overall OCD diagnoses are listed in the right column.

The prevalence rates of the overall diagnosis of OCD varied between $1.3 \%$ (PsyCoLaus), $5.8 \%$ (ZInEP), and $7.8 \%$ (Zurich Study). While the rates for the MOCS were nearly the same in the ZInEP (4.0\%) and the Zurich Study samples $(3.7 \%)$, the PsyCoLaus sample displayed distinctly lower rates $(0.9 \%)$. The PCS ranged between $0.3 \%$ (PsyCoLaus) and $4.0 \%$ (Zurich Study). 
Table 1 Comparison of socio-demographic characteristics of the pure compulsive subtype, the mixed obsessive-compulsive subtype, and the overall OCD diagnosis between the Zurich Study, ZInEP, and PsyCoLaus

\begin{tabular}{|c|c|c|c|c|c|c|c|c|c|}
\hline \multirow[t]{2}{*}{ ' } & \multicolumn{3}{|c|}{ Zurich Study } & \multicolumn{3}{|l|}{ ZInEP } & \multicolumn{3}{|l|}{ PsyCoLaus } \\
\hline & $\begin{array}{l}\text { Pure } \\
\text { compulsive } \\
\text { subtype }\end{array}$ & $\begin{array}{l}\text { Mixed } \\
\text { obsessive- } \\
\text { compulsive } \\
\text { subtype }\end{array}$ & $\begin{array}{l}\text { Overall } \\
\text { OCD }\end{array}$ & $\begin{array}{l}\text { Pure } \\
\text { compulsive } \\
\text { subtype }\end{array}$ & $\begin{array}{l}\text { Mixed } \\
\text { obsessive- } \\
\text { compulsive } \\
\text { subtype }\end{array}$ & Overall OCD & $\begin{array}{l}\text { Pure } \\
\text { compulsive } \\
\text { subtype }\end{array}$ & $\begin{array}{l}\text { Mixed } \\
\text { obsessive- } \\
\text { compulsive } \\
\text { subtype }\end{array}$ & $\begin{array}{l}\text { Overall } \\
\text { OCD }^{f}\end{array}$ \\
\hline Prevalence $(n)$ & 33 & 35 & 68 & 33 & 78 & 111 & 12 & 33 & 47 \\
\hline $\begin{array}{l}\text { Age at onset } \\
\text { (mean) }\end{array}$ & $13.8^{\mathrm{a}}$ & $23.5^{\mathrm{a}}$ & $18.4^{\mathrm{a}}$ & $16.1^{\mathrm{a}}$ & $19.8^{\mathrm{a}}$ & $18.8^{\mathrm{a}}$ & 18.4 & 22.2 & 21.7 \\
\hline \multicolumn{10}{|l|}{ Sex, $n(\%)$} \\
\hline Males & $14\left(32.9^{\mathrm{a}}\right)$ & $16\left(37.8^{\mathrm{a}}\right)$ & $30\left(35.3^{\mathrm{a}}\right)$ & $21\left(77.6^{\mathrm{a}}\right)$ & $31\left(43.5^{\mathrm{a}}\right)$ & $52\left(53.8^{\mathrm{a}}\right)$ & $3(25.0)$ & $12(36.4)$ & $16(34.0)$ \\
\hline Females & $19\left(67.1^{\mathrm{a}}\right)$ & $19\left(62.2^{\mathrm{a}}\right)$ & $38\left(64.7^{\mathrm{a}}\right)$ & $12\left(22.4^{\mathrm{a}}\right)$ & $47\left(56.5^{\mathrm{a}}\right)$ & $59\left(46.2^{\mathrm{a}}\right)$ & $9(75.0)$ & $21(63.6)$ & $31(66.0)$ \\
\hline \multicolumn{10}{|c|}{ Education, $n(\%)^{\mathrm{b}, \mathrm{e}}$} \\
\hline Low & $16\left(44.6^{\mathrm{a}}\right)$ & $22\left(65.3^{\mathrm{a}}\right)$ & $38\left(54.5^{\mathrm{a}}\right)$ & $13\left(54.1^{\mathrm{a}}\right)$ & $36\left(56.3^{\mathrm{a}}\right)$ & $49\left(55.6^{\mathrm{a}}\right)$ & $5(45.5)$ & $18(54.5)$ & $24(52.2)$ \\
\hline Medium & $10\left(48.7^{\mathrm{a}}\right)$ & $5\left(15.8^{\mathrm{a}}\right)$ & $15\left(32.9^{\mathrm{a}}\right)$ & $12\left(31.1^{\mathrm{a}}\right)$ & $31\left(38.9^{\mathrm{a}}\right)$ & $43\left(36.5^{\mathrm{a}}\right)$ & $3(27.3)$ & $6(18.2)$ & $10(21.7)$ \\
\hline High & $7\left(6.7^{\mathrm{a}}\right)$ & $8\left(18.9^{\mathrm{a}}\right)$ & $15\left(12.5^{\mathrm{a}}\right)$ & $8\left(14.9^{\mathrm{a}}\right)$ & $11\left(4.8^{\mathrm{a}}\right)$ & $19\left(7.9^{\mathrm{a}}\right)$ & $3(27.3)$ & $9(27.3)$ & $12(26.1)$ \\
\hline \multicolumn{10}{|c|}{ Marital status $n(\%)^{\mathrm{d}, \mathrm{e}}$} \\
\hline Married & $7\left(11.8^{\mathrm{a}}\right)$ & $12\left(56.1^{\mathrm{a}}\right)$ & $19\left(36.8^{\mathrm{a}}\right)$ & $7\left(20.5^{\mathrm{a}}\right)$ & $19\left(31.1^{\mathrm{a}}\right)$ & $26\left(27.9^{\mathrm{a}}\right)$ & $7(58.3)$ & $15(45.5)$ & 23 (48.9) \\
\hline Else $^{c}$ & $11\left(88.2^{\mathrm{a}}\right)$ & $13\left(43.9^{\mathrm{a}}\right)$ & $24\left(63.2^{\mathrm{a}}\right)$ & $26\left(79.5^{a}\right)$ & $59\left(68.9^{a}\right)$ & $85\left(72.1^{\mathrm{a}}\right)$ & $5(41.7)$ & $18(54.5)$ & $24(51.1)$ \\
\hline
\end{tabular}

${ }^{a}$ Weighted

${ }^{\text {b }}$ Low: primary level (e.g., mandatory school graduation, apprenticeship), medium: secondary level (e.g., secondary school, technical school, university of applied sciences), high: high level (e.g., university, Swiss Federal Institute of Technology Zurich)

${ }^{c}$ Else: single, divorced, separated, widowed

d Marital status in the Zurich Study according to the last survey in 2008

e Discrepancies in total numbers result from missing items

f $n=2$ subjects could not be explicitly assigned to either the PCS or the MS

The mean age of onset was consistently lower in the PCS, with a particularly skewed gradient in the Zurich Study. The sex ratio did not differ significantly between the distinct OCD subtypes in either the PsyCoLaus or the Zurich Study. However, there was a significantly lower preponderance of females with pure compulsions in the ZInEP survey. No further socio-demographic feature was significantly associated either with the distinctive OCD subtypes or with the overall diagnosis of OCD (results not shown).

In all three samples, familial aggregation of CMD yielded numerous associations with the MOCS, but hardly any associations with pure compulsions. Indeed, parental anxiety, depression, and panic were consistently associated with the MOCS in the current study. The parental risk of having a diagnosis of OCD was highest in the MOCS, albeit only significantly so in the ZInEP sample. Childhood adversities were likewise cumulated within the MOCS. However, the PCS was silhouetted against the MOCS by positive associations with school-related fears (Zurich Study, ZInEP), and, in contrast to the MOCS, with popularity in the neighborhood and financial resources in the family (ZInEP).
The associations related to comorbidity mainly gathered around the MOCS, independently of the sample. Yet, in ZInEP and PsyCoLaus, specific phobias were also associated with the PCS, and, similarly, stuttering in the ZInEP survey. The comorbidity patterns appear to be more diverse in PsyCoLaus. However, this should be interpreted with caution because of the small sample sizes of the subtypes and the large confidence intervals.

The table below illustrates the comorbidity patterns of the pooled dataset (Table 10). An asterisk refers to a significant Breslow-Day test, indicating that a random effect model (right column) is more appropriate compared with a fixed effect model (left column). It can be seen from the data that the main results did not differ considerably from the analysis of the three separate datasets Zurich Study, ZInEP, and PsyCoLaus. The results of the pooled data still provided evidence for a high burden within the MOCS compared with the PCS. However, in the analyses of pooled data, not only specific phobias but also agoraphobia and social phobia were significantly associated with the PCS. Obviously, this effect resulted from the PsyCoLaus sample. 
Table 2 Socio-demographic marker variables and risk factors related to obsessive-compulsive disorder (OCD) in the Zurich Study 1979-2008

\begin{tabular}{|c|c|c|c|}
\hline & \multicolumn{2}{|c|}{ Distinctive subtyping } & \multirow[t]{2}{*}{ Overall OCD } \\
\hline & Pure compulsions & Mixed obsessive-compulsive & \\
\hline \multicolumn{4}{|l|}{ Prevalence } \\
\hline$n$ & 33 & 35 & 68 \\
\hline Rate (weighted, $95 \%$ CI) & $4.0(1.8-6.3)$ & $3.7(1.6-5.8)$ & $7.8(4.7-10.8)$ \\
\hline \multicolumn{4}{|l|}{ Socio-demographic characteristics } \\
\hline \multicolumn{4}{|l|}{ Sex } \\
\hline Females:males (weighted, ORs, $95 \%$ CI) & $2.0(0.6-6.7)$ & $1.6(0.5-5.3)$ & $1.9(0.8-4.4)$ \\
\hline Age at onset (mean, weighted, $95 \% \mathrm{CI}$ ) & $13.8(9.3-18.3)$ & $23.5(17.8-29.2)$ & $18.4(13.5-23.4)$ \\
\hline \multicolumn{4}{|c|}{ Familial psychopathology (weighted, ORs, $95 \%$ CI) } \\
\hline Parents mentally ill & $1.8(0.4-7.3)$ & $1.9(0.5-7.4)$ & $1.9(0.7-5.2)$ \\
\hline OCD & $1.5(0.3-6.8)$ & $1.6(0.3-7.6)$ & $1.6(0.4-5.7)$ \\
\hline Phobias & $2.3(0.7-7.9)$ & $1.4(0.4-5.3)$ & $1.9(0.8-4.8)$ \\
\hline Anxiety & $1.1(0.3-3.8)$ & $5.7(1.7-18.3)$ & $2.6(1.0-6.5)$ \\
\hline Panic & $0.5(0.5-1.9)$ & $6.9(1.5-32.2)$ & $3.0(0.8-11.8)$ \\
\hline Depression & $2.8(0.8-9.9)$ & $4.0(1.1-14.3)$ & $3.5(1.4-8.8)$ \\
\hline Alcohol abuse & $2.7(0.6-12.0)$ & $2.7(0.6-11.8)$ & $2.9(1.0-8.6)$ \\
\hline Smoking & $1.6(0.3-7.8)$ & $0.4(0.1-1.5)$ & $0.7(0.3-2.1)$ \\
\hline \multicolumn{4}{|l|}{ Adversities in family (weighted, ORs, $95 \%$ CI) } \\
\hline More severely punished than others & $0.4(0.1-1.3)$ & $1.4(0.2-9.1)$ & $0.8(0.2-3.7)$ \\
\hline Parents did not care enough & $0.4(0.1-1.4)$ & $0.6(0.2-1.7)$ & $0.5(0.2-1.1)$ \\
\hline Quarrels between parents & $1.5(0.4-5.9)$ & $3.0(0.8-11.1)$ & $2.3(0.8-6.0)$ \\
\hline \multicolumn{4}{|l|}{ Other adversity (weighted, ORs, $95 \% \mathrm{CI}$ ) } \\
\hline Afraid of gym or swimming & $7.2(1.8-28.5)$ & $6.6(1.5-28.9)$ & $8.7(2.9-26.0)$ \\
\hline Expelled or unpopular (youth) & $1.9(0.4-9.1)$ & $5.7(1.5-21.9)$ & $3.8(1.3-10.9)$ \\
\hline Fear of teacher & $6.1(1.7-21.6)$ & $0.8(0.2-4.1)$ & $2.8(1.1-7.2)$ \\
\hline
\end{tabular}

Bold: $p<0.05$

$O C D$ obsessive-compulsive disorder, $O R$ odds ratio, $C I$ confidence interval

\section{Discussion}

The present study examined a broad spectrum of psychosocial risk factors and comorbidity patterns to characterize two distinctive OCD subtypes, i.e., the PCS and the MOCS (comprising obsessions with/without compulsions). This was the first study to explore distinctive instead of overlapping OCD subtypes. The analyses were repeated in three community samples from Switzerland, two of them crosssectional and one longitudinal. A final analysis of pooled data enlarging the statistical power confirmed the comorbidity patterns derived from the separate samples.

From a nosological point of view, a specific classification approach of subtypes is successful if it consistently differentiates better than other approaches, for example, by delivering maximally different association patterns. In fact, the overall patterns related to distinctive OCD subtypes in this study revealed a fairly consistent general picture across different samples. In all three samples, the PCS comprising persons with pure compulsions showed scarce associations to other factors and variables, whereas the MOCS was characterized by a large number of associations with childhood adversities, familial burden, and numerous comorbid disorders. In other terms, PCS and MOCS shared almost no common characteristics. Across the association patterns examined in this study, notably emphasizing patterns in this instance and not specific associations, the PCS and MOCS appear to represent two completely different entities.

From a methodological point of view, the pure subtypes determined in some disorders, such as specific phobias [3] or, in this study, OCD, can been seen as psychopathological extreme variants. They offer an interesting opportunity to learn about specifically involved neural circuits, neurotransmission or hormonal mechanisms, genetics, and, possibly, immunological levers.

The general picture immediately begs the question as to what the PCS and MOCS might represent, i.e., whether they relate to a specific etiopathogenesis and to specific outcomes. In the following sections, we will address 
Table 3 Comorbidity patterns in obsessive-compulsive disorder (OCD) in the Zurich Study 1979-2008

\begin{tabular}{|c|c|c|c|}
\hline & \multicolumn{2}{|c|}{ Distinctive subtyping } & \multirow[t]{2}{*}{ Overall OCD } \\
\hline & $\begin{array}{l}\text { Pure } \\
\text { compulsions }\end{array}$ & $\begin{array}{l}\text { Mixed obsessive- } \\
\text { compulsive }\end{array}$ & \\
\hline UP & $2.6(0.7-9.6)$ & $1.3(0.3-6.0)$ & $2.0(0.7-5.3)$ \\
\hline BIP & $3.6(0.8-17.3)$ & $7.0(1.6-31.6)$ & $6.1(1.8-19.9)$ \\
\hline Dysthymia & $1.7(0.5-5.3)$ & $6.7(1.3-34.4)$ & $4.3(1.2-15.6)$ \\
\hline Neurasthenia & $0.9(0.3-2.8)$ & $3.7(0.8-17.2)$ & $2.2(0.7-7.3)$ \\
\hline GAD & $1.7(0.5-6.4)$ & $4.4(1.3-14.4)$ & $2.9(1.2-7.1)$ \\
\hline Agoraphobia & $0.5(0.2-1.9)$ & $7.6(2.0-29.2)$ & $3.3(1.1-10.6)$ \\
\hline Specific phobia & $1.7(0.4-7.3)$ & $3.4(0.8-13.5)$ & $2.6(0.9-7.4)$ \\
\hline Social phobia & $1.2(0.4-3.1)$ & $6.8(1.9-24.0)$ & $3.6(1.3-9.6)$ \\
\hline Panic disorder & $0.9(0.2-3.7)$ & $7.5(1.4-38.9)$ & $3.9(0.9-16.2)$ \\
\hline Binge eating & $0.5(0.2-1.7)$ & $1.0(0.4-2.8)$ & $0.7(0.3-1.7)$ \\
\hline Marijuana abuse & $0.5(0.2-1.5)$ & $3.7(0.9-14.6)$ & $1.8(0.6-5.6)$ \\
\hline Heavy smoking & $1.7(0.5-6.5)$ & $1.3(0.3-4.7)$ & $1.5(0.6-4.0)$ \\
\hline Alcohol abuse & $0.8(0.2-3.1)$ & $1.2(0.4-4.1)$ & $1.0(0.4-2.5)$ \\
\hline Illicit drugs abuse & $0.2(0.0-1.0)$ & $4.5(1.0-19.4)$ & $1.9(0.5-7.1)$ \\
\hline
\end{tabular}

Weighted, odds ratios, $95 \%$ confidence interval; bold: $p<0.05$

$U P$ unipolar depression, $B I P$ bipolar disorder, $G A D$ generalized anxiety disorder

Table 4 Associations between other scales and obsessive-compulsive disorder (OCD) in the Zurich Study 1979-2008

\begin{tabular}{llll}
\hline & \multicolumn{2}{l}{ Distinctive subtyping } & Overall OCD \\
\cline { 2 - 3 } & Pure compulsions & Mixed obsessive-compulsive & \\
\hline SNS & $2.0(0.6-6.7)$ & $1.6(0.5-5.3)$ & $1.9(0.8-4.4)$ \\
STS & $2.0(0.6-6.7)$ & $1.6(0.5-5.3)$ & $1.9(0.8-4.4)$ \\
\hline
\end{tabular}

Weighted, odds ratios, $95 \%$ confidence interval

SNS schizophrenia nuclear symptoms, SCL-90-subscale [20, 59]; dichotomized into continuously high scores versus other, STS schizotypal signs, SCL-90-subscale [20, 59]; dichotomized into continuously high scores versus other

several points that might prove helpful in providing preliminary answers.

\section{Prevalences}

Both the ZInEP and the PsyCoLaus data revealed more than twofold higher frequencies for the MOCS than for the PCS. In contrast, the distribution between these two subtypes was nearly equal in the Zurich Study. More detailed analyses focusing on the equal proportion of pure and mixed cases in the Zurich Study indicated that pure compulsions were mostly assessed in young adulthood, when the subjects were in their twenties (results not shown). Consequently, two possible explanations can be put forward to explain the disparity between the samples: (1) the initially pure compulsive individuals developed obsessions over time and thus switched to the MOCS and (2) the young subjects belonging to the PCS dropped out of the study or missed one or more follow-ups, making it impossible to assess later occurring obsessive symptoms. Despite there were fewer subjects belonging to the PCS, the latter represented $26 \%$ (PsyCoLaus), $30 \%$ (ZInEP), and $49 \%$ (Zurich Study) of all OCD cases, showing that this subtype is anything but rare.

\section{Socio-demographic factors}

The socio-demographic risk factors sex and age of onset showed similarities and discrepancies between the three samples. The PCS consistently revealed a lower age of onset in all three samples. At the same time, a significant sex ratio with fewer females in the PCS was found, however, only in ZInEP. Congruently with our pure subtype, Fineberg et al. [24] demonstrated with the Zurich Study that males were younger than females at onset of any obsessive-compulsive symptomatology. A review focusing on age of onset suggested that early onset (mean onset 11 years) versus late onset (mean onset 23 years) defines two distinct subtypes of OCD with approximately three quarters of cases showing an early onset [64]. The approximately equal gender ratio or slight predominance of women with OCD found in PsyCoLaus, and the Zurich Study are in line with previous evidence [7, 28, 37].

\section{Familial burden}

A blind, controlled family study [44] showed that agoraphobia, GAD, panic disorder, separation anxiety disorder (SAD), and recurrent major depression were more frequent in OCD case relatives compared with control relatives. However, only agoraphobia and GAD occurred independently of OCD. The authors concluded that agoraphobia, GAD, and OCD share a common familial etiology in contrast to the other anxiety disorders, which may instead be a consequence of OCD or which might manifest a more complex syndrome [44]. Based on our findings, we conclude that these common associations between agoraphobia, GAD, and OCD could have resulted from the MOCS including subjects suffering from obsessions with/without compulsions.

\section{Childhood adversities}

The analyses with respect to childhood adversities were striking. The MOCS showed more overall adversities, with the exception of school-related fears, which also occurred frequently in the PCS (Zurich Study, ZInEP sample).

Considering the disrupted school performance $[16,17$, $62,65]$ and the tendency of OCD affected school-age children to hide their OCD behaviors due to embarrassment 
Table 5 Socio-demographic marker variables and risk factors related to obsessive-compulsive disorder (OCD) diagnoses subtypes in ZInEP

\begin{tabular}{|c|c|c|c|}
\hline & \multicolumn{2}{|c|}{ Distinctive subtyping } & \multirow[t]{2}{*}{ Overall OCD } \\
\hline & Pure compulsions & Mixed obsessive-compulsive & \\
\hline \multicolumn{4}{|l|}{ Prevalence } \\
\hline$n$ & 33 & 78 & 111 \\
\hline Rate (weighted, $95 \%$ CI) & $1.7(0.9-2.6)$ & $4.0(2.7-5.3)$ & $5.8(4.2-7.3)$ \\
\hline \multicolumn{4}{|l|}{ Socio-demographic characteristics } \\
\hline Age at onset (mean, weighted, $95 \% \mathrm{CI}$ ) & $16.1(11.5-20.6)$ & $19.8(17.0-22.5)$ & $18.8(16.3-21.3)$ \\
\hline \multicolumn{4}{|l|}{ Sex } \\
\hline Females:males (weighted, ORs, $95 \%$ CI) & $0.3(0.1-0.8)$ & $1.3(0.7-2.6)$ & $0.8(0.5-1.5)$ \\
\hline \multicolumn{4}{|l|}{ Language (weighted, ORs, $95 \% \mathrm{CI}$ ) } \\
\hline Dyslexia score & $1.0(0.9-1.0)$ & $1.0(0.9-1.0)$ & $1.0(0.9-1.0)$ \\
\hline Stuttering & $4.5(1.0-19.6)$ & $1.9(0.4-8.3)$ & $2.7(0.9-8.0)$ \\
\hline Difficulties reading, writing & $0.6(0.2-2.3)$ & $0.6(0.3-1.4)$ & $0.6(0.3-1.2)$ \\
\hline \multicolumn{4}{|c|}{ Familial psychopathology (weighted, ORs, $95 \%$ CI) } \\
\hline Hyperactivity & $0.2(0.1-1.2)$ & $4.4(2.0-9.6)$ & $2.7(1.3-5.5)$ \\
\hline Specific phobia & $1.9(0.7-5.4)$ & $1.3(0.6-2.6)$ & $1.5(0.8-2.7)$ \\
\hline Panic attacks & $1.1(0.3-4.3)$ & $2.5(1.1-5.7)$ & $2.0(1.0-4.2)$ \\
\hline Other anxiety disorders & $0.5(0.2-1.4)$ & $1.7(0.8-3.6)$ & $1.3(0.7-2.4)$ \\
\hline Depressive disorders & $0.4(0.1-1.0)$ & $2.4(1.2-4.6)$ & $1.4(0.8-2.5)$ \\
\hline Bipolar disorders & $0.4(0.1-1.6)$ & $0.6(0.2-1.9)$ & $0.5(0.2-1.3)$ \\
\hline OCD & $1.5(0.4-5.2)$ & $2.8(1.3-6.3)$ & $2.4(1.2-4.8)$ \\
\hline Schizophrenia, psychosis & $0.7(0.1-3.0)$ & $1.1(0.4-3.3)$ & $1.0(0.4-2.5)$ \\
\hline Eating disorder & $2.5(0.7-8.7)$ & $0.8(0.3-2.2)$ & $1.3(0.6-2.9)$ \\
\hline Alcohol abuse & $0.3(0.1-0.9)$ & $2.4(1.1-5.5)$ & $1.6(0.7-3.2)$ \\
\hline Medicament abuse & $2.2(0.4-11.9)$ & $1.7(0.5-6.1)$ & $1.9(0.7-5.5)$ \\
\hline Illicit drugs abuse & $1.6(0.3-8.7)$ & $6.1(2.4-15.5)$ & $4.6(2.0-10.7)$ \\
\hline Heavy smoking & $0.7(0.3-2.0)$ & $2.5(1.3-4.9)$ & $1.7(1.0-3.1)$ \\
\hline \multicolumn{4}{|l|}{ CTQ (weighted, ORs, $95 \%$ CI) } \\
\hline Emotional abuse & $1.0(0.6-1.8)$ & $1.8(1.2-2.7)$ & $1.7(1.2-2.4)$ \\
\hline Emotional neglect & $0.9(0.5-1.6)$ & $1.5(1.1-2.1)$ & $1.4(1.0-1.9)$ \\
\hline Physical abuse & $0.5(0.0-5.3)$ & $2.0(1.0-4.1)$ & $1.8(0.9-3.5)$ \\
\hline Physical neglect & $0.5(0.1-1.9)$ & $2.3(1.0-5.0)$ & $1.8(0.8-3.8)$ \\
\hline Sexual abuse & $0.1(0.0-1.6)$ & $1.0(0.5-2.1)$ & $0.9(0.4-1.9)$ \\
\hline \multicolumn{4}{|c|}{ Other childhood adversities (weighted ORs, $95 \% \mathrm{CI}$ ) } \\
\hline Family had enough money & $7.0(0.9-54.8)$ & $0.3(0.1-0.8)$ & $0.4(0.2-1.1)$ \\
\hline Family was popular in the neighborhood & $4.0(1.1-14.5)$ & $0.5(0.2-1.2)$ & $0.7(0.3-1.5)$ \\
\hline Parents quarreled often & $1.2(0.4-3.8)$ & $1.9(0.9-4.1)$ & $1.7(0.9-3.4)$ \\
\hline Often punished & $0.4(0.1-1.3)$ & $1.7(0.8-3.8)$ & $1.3(0.7-2.7)$ \\
\hline Runaway from home & $1.1(0.3-3.4)$ & $2.6(1.1-6.3)$ & $2.2(1.0-4.8)$ \\
\hline Often punished/criticized by teacher & $0.3(0.1-1.8)$ & $2.8(1.2-6.6)$ & $2.1(1.0-4.6)$ \\
\hline Fear of school & $3.4(1.0-11.8)$ & $4.6(2.0-10.3)$ & $4.5(2.2-9.1)$ \\
\hline Fear of swimming/gym & $1.2(0.5-3.4)$ & $3.3(1.5-7.0)$ & $2.7(1.4-5.3)$ \\
\hline Problems/quarrels with peers & $3.0(0.8-11.9)$ & $1.4(0.5-4.2)$ & $1.8(0.8-4.3)$ \\
\hline Blows from others/peers & $1.0(0.4-2.8)$ & $2.6(1.1-5.7)$ & $2.1(1.1-4.3)$ \\
\hline Popular in the neighborhood (children) & $1.2(0.4-3.2)$ & $0.5(0.2-1.0)$ & $0.6(0.3-1.1)$ \\
\hline
\end{tabular}

Bold: $p<0.05$

$O R$ odds ratio, $C I$ confidence interval, $O C D$ obsessive-compulsive disorder, $C T Q$ Childhood Trauma Questionnaire 
Table 6 Comorbidity patterns in obsessive-compulsive disorder in ZInEP

\begin{tabular}{llll}
\hline & \multicolumn{2}{l}{ Distinctive subtyping } & Overall OCD \\
\cline { 2 - 3 } & Pure compulsions & Mixed obsessive-compulsive & \\
\hline MDD & $0.8(0.2-2.0)$ & $\mathbf{2 . 8}(\mathbf{1 . 4}-\mathbf{5 . 6})$ & $\mathbf{2 . 1}(\mathbf{1 . 5}-\mathbf{3 . 9})$ \\
UP & $0.7(0.2-2.0)$ & $\mathbf{2 . 3}(\mathbf{1 . 0}-\mathbf{5 . 0})$ & $1.7(0.9-3.5)$ \\
Dysthymia & $\mathrm{n} / \mathrm{a}$ & $0.6(0.1-2.6)$ & $0.4(0.1-1.8)$ \\
Neurasthenia & $0.6(0.1-2.9)$ & $\mathbf{4 . 7}(\mathbf{1 . 9}-\mathbf{1 1 . 6})$ & $\mathbf{3 . 3}(\mathbf{1 . 4}-\mathbf{7 . 6})$ \\
Bipolar disorder (bridge def.) & $2.1(0.5-8.4)$ & $1.9(0.6-5.8)$ & $2.0(0.8-5.1)$ \\
Panic & $\mathrm{n} / \mathrm{a}$ & $2.4(0.9-6.7)$ & $1.6(0.6-4.4)$ \\
GAD & $3.1(0.6-15.2)$ & $\mathbf{2 . 9}(\mathbf{1 . 0}-\mathbf{8 . 6})$ & $\mathbf{3 . 1}(\mathbf{1 . 3}-\mathbf{7 . 8})$ \\
Agoraphobia & $\mathrm{n} / \mathrm{a}$ & $2.5(0.9-6.4)$ & $1.7(0.7-4.3)$ \\
Social phobia & $2.4(0.5-11.0)$ & $\mathbf{4 . 5}(\mathbf{1 . 9}-\mathbf{1 0 . 3})$ & $\mathbf{4 . 0}(\mathbf{1 . 9}-\mathbf{8 . 4})$ \\
Specific phobia & $\mathbf{4 . 3}(\mathbf{1 . 5}-\mathbf{1 2 . 4})$ & $1.3(0.6-2.8)$ & $\mathbf{2 . 1}(\mathbf{1 . 1}-\mathbf{4 . 0})$ \\
Binge eating & $\mathrm{n} / \mathrm{a}$ & $3.2(0.6-17.2)$ & $2.2(0.4-11.5)$ \\
Daily smoking & $1.0(0.4-2.7)$ & $1.6(0.8-3.2)$ & $1.4(0.8-2.5)$ \\
Alcohol dependence/abuse & $4.6(0.8-26.3)$ & $0.8(0.3-2.5)$ & $1.9(0.6-6.5)$ \\
\hline
\end{tabular}

Weighted, odds ratios, $95 \%$ confidence interval; bold: $p<0.05$

$M D D$ major depressive disorder, $U P$ unipolar depression, $G A D$ generalized anxiety disorder, $O C D$ obsessive-compulsive disorder, $n / a$ not available

Table 7 Associations between other scales and obsessive-compulsive disorder in ZInEP

\begin{tabular}{|c|c|c|c|}
\hline & \multicolumn{2}{|c|}{ Distinctive subtyping } & \multirow{2}{*}{ Overall OCD } \\
\hline & Pure compulsions & Mixed obsessive-compulsive & \\
\hline ADHD SRBQ (adulthood) & $1.00(0.99-1.08)$ & $1.06(1.02-1.11)$ & $1.06(1.02-1.09)$ \\
\hline ADHD WURS (childhood) & $1.00(0.97-1.03)$ & $1.04(1.02-1.06)$ & $1.03(1.01-1.05)$ \\
\hline SNS & $1.21(0.58-2.53)$ & $2.38(1.60-3.54)$ & $2.10(1.44-3.07)$ \\
\hline STS & $1.67(0.97-2.88)$ & $1.91(1.32-2.78)$ & $1.88(1.36-2.60)$ \\
\hline PTSD relevant events (sum) & $0.76(0.46-1.27)$ & $1.19(0.96-1.48)$ & $1.11(0.91-1.35)$ \\
\hline
\end{tabular}

Odds ratios, $95 \%$ confidence interval; bold: $p<0.05$

$A D H D$ attention-deficit hyperactivity disorder, $S R B Q$ self-rating behavior questionnaire, WURS wender-utah-rating-scale [53, 55], SNS schizophrenia nuclear symptoms, SCL-90-subscale [20, 59], STS schizotypal signs, SCL-90-subscale [20, 59], PTSD posttraumatic stress disorder, PTSD screening scale [15]

[32], the association of pure compulsions and mixed obsessive-compulsive symptom presentations, respectively, with the school environment appears plausible. A remarkable difference was found in the ZInEP sample: Whereas the families of the PCS were positively associated with items assessing popularity in the neighborhood and financial resources, the opposite was the case for the MOCS. Furthermore, subjects belonging to the MOCS revealed limited popularity in the neighborhood during their childhood, indicating reduced social functioning compared with the PCS. These findings could represent a proxy for the increased illness severity of the more complex MOCS.

\section{Comorbid disorders}

Angst et al. [7] found particularly high associations between OCD and certain anxiety disorders (GAD, panic attacks, and social phobia), bipolar disorders (especially bipolar II disorders), but not depression. This latter finding conflicted with other studies showing a clear association between OCD and depression [44, 61, 66]. We were able to refine Angst et al.'s [7] Zurich Study findings by showing that the association between OCD and bipolar disorder was most pronounced in the MOCS. However, the MOCS was associated with both bipolar disorder and unipolar depression in the PsyCoLaus survey, and in the ZInEP sample, the association was even restricted to unipolar depression. A possible explanation for these contradictory results could derive from differing definitions of bipolar disorder (DSM vs. definition from the Bridge Study [5]), and differing calculations of prevalence rates (cumulative vs. 12 months vs. lifetime), respectively. Therefore, the question of whether the association between OCD and depression might be an artifact of the heterogeneity of 
Table 8 Socio-demographic marker variables and risk factors related to obsessivecompulsive disorder diagnosis subtypes in PsyCoLaus

\begin{tabular}{|c|c|c|c|}
\hline & \multicolumn{2}{|l|}{ Distinctive subtyping } & \multirow[t]{2}{*}{ Overall OCD } \\
\hline & Pure compulsions & Mixed obsessive-compulsive & \\
\hline \multicolumn{4}{|l|}{ Prevalence } \\
\hline$n$ & 12 & 33 & $47^{\mathrm{c}}$ \\
\hline Rate $(95 \% \mathrm{CI})$ & $0.32(0.14-0.50)$ & $0.89(0.59-1.19)$ & $1.27(0.91-1.63)$ \\
\hline \multicolumn{4}{|c|}{ Socio-demographic characteristics } \\
\hline Age at onset (mean, SD) & $18.42(11.73-25.11)$ & $22.19(16.90-27.41)$ & $21.72(17.61-25.78)$ \\
\hline \multicolumn{4}{|l|}{ Sex (ORs, $95 \%$ CI) } \\
\hline Females:males & $2.67(0.72-9.89)$ & $1.56(0.77-3.18)$ & $1.73(0.94-3.17)$ \\
\hline \multicolumn{4}{|l|}{ Education (ORs, $95 \%$ CI) } \\
\hline Low $^{\mathrm{a}}$ & $0.68(0.16-2.84)$ & $0.81(0.36-1.81)$ & $0.81(0.40-1.63)$ \\
\hline Medium $^{\mathrm{b}}$ & $0.87(0.18-4.33)$ & $0.58(0.20-1.63)$ & $0.72(0.31-1.68)$ \\
\hline University (ref.) & - & - & \\
\hline \multicolumn{4}{|l|}{ Language (ORs, $95 \%$ CI) } \\
\hline Speech disorder & $2.69(0.35-21.04)$ & $1.92(0.45-8.11)$ & $2.04(0.62-6.67)$ \\
\hline Stuttering & $3.03(0.39-23.68)$ & $1.04(0.14-7.65)$ & $1.47(0.35-6.15)$ \\
\hline \multicolumn{4}{|c|}{ Familial psychopathology (ORs, $95 \%$ CI) } \\
\hline Depression (parents) & $3.24(1.02-10.24)$ & $3.30(1.61-6.77)$ & $3.37(1.85-6.13)$ \\
\hline Depression (family) & $1.19(0.32-4.39)$ & $3.00(1.51-5.99)$ & $2.45(1.36-4.40)$ \\
\hline Anxiety (family) & $3.31(0.89-12.27)$ & $6.62(3.26-13.44)$ & $5.89(3.21-10.80)$ \\
\hline Bipolar disorder (family) & $\mathrm{n} / \mathrm{a}$ & $4.76(1.64-13.78)$ & $3.18(1.12-9.02)$ \\
\hline OCD (family) & $\mathrm{n} / \mathrm{a}$ & $3.23(0.43-24.32)$ & $2.23(0.30-16.61)$ \\
\hline Schizophrenia (family) & $\mathrm{n} / \mathrm{a}$ & $4.39(1.02-18.81)$ & $2.99(0.71-12.66)$ \\
\hline \multicolumn{4}{|c|}{ Other childhood adversities (ORs, $95 \%$ CI) } \\
\hline Quarrels between parents & $3.06(0.92-10.21)$ & $3.09(1.49-6.42)$ & $2.95(1.58-5.48)$ \\
\hline Fear of parental punishment & $2.83(0.76-10.49)$ & $4.94(2.41-10.13)$ & $4.13(2.22-7.70)$ \\
\hline Run away from home & $2.74(0.35-21.41)$ & $1.95(0.46-8.25)$ & $2.11(0.65-6.91)$ \\
\hline Death of mother & $\mathrm{n} / \mathrm{a}$ & $1.02(0.14-7.50)$ & $0.71(0.10-5.17)$ \\
\hline Death of father & $\mathrm{n} / \mathrm{a}$ & $1.76(0.53-5.82)$ & $1.21(0.37-3.95)$ \\
\hline General childhood & $1.74(0.95-3.17)$ & $1.47(0.99-2.19)$ & $1.54(1.11-2.13)$ \\
\hline Children's home & $1.02(0.13-7.91)$ & $1.12(0.34-3.69)$ & $1.05(0.37-2.95)$ \\
\hline
\end{tabular}

Bold: $p<0.05$

$O R$ odds ratio, $C I$ confidence interval, $O C D$ obsessive-compulsive disorder, $n / a$ not available

${ }^{\text {a }}$ Compulsory, apprenticeship, low-level high school

${ }^{\mathrm{b}}$ Upper-level high school, teacher, technician, applied sciences

c $n=2$ subjects could not be explicitly assigned to either PCS or MS depression, including unidentified bipolars [7], needs more detailed investigation.

A clear pattern found in all three samples was the association of GAD, social phobia, agoraphobia, and panic with the MOCS. Oversensitivity as a personality trait and anxiety were hypothesized to explain the comorbid occurrence of OCD and these comorbid disorders [7]. Our results suggest that this mainly applies to the MOCS. The only consistent comorbidity pattern associated with the PCS was found with regard to specific phobias in ZInEP and PsyCoLaus. The additional information concerning childhood adversities indicated that these phobias could refer to school-related fears.
Surprisingly, we did not find any consistent relation between the OCD subtypes and eating disorders, although these disorders frequently co-occurred in previous studies, which was explained by a etiological relationship [4]. Again, the disparity between our samples may have led to this discrepancy (binge eating in ZInEP and Zurich Study vs. bulimia and anorexia nervosa in PsyCoLaus). The inverse relationship with more anorexia nervosa in the PCS and more bulimia in the MOCS (PsyCoLaus sample) were based on only a few cases and therefore require replication. Nevertheless, the following considerations are noteworthy: Cumulative evidence showed that impulsivity is linked to OCD [4]. Subjects with bulimia and anorexia-binge/ 
Table 9 Comorbidity patterns in diagnosis subtypes of obsessive-compulsive disorder in PsyCoLaus

\begin{tabular}{|c|c|c|c|}
\hline & \multicolumn{2}{|l|}{ Distinctive subtyping } & \multirow{2}{*}{ Overall OCD } \\
\hline & Pure compulsions & Mixed obsessive-compulsive & \\
\hline MDD & $2.58(0.78-8.59)$ & $2.27(1.11-4.63)$ & $2.30(1.26-4.18)$ \\
\hline Dysthymia & $\mathrm{n} / \mathrm{a}$ & $\mathrm{n} / \mathrm{a}$ & $\mathrm{n} / \mathrm{a}$ \\
\hline Tourette syndrome & $3.42(0.44-26.75)$ & $3.82(1.15-12.74)$ & $3.60(1.26-10.23)$ \\
\hline Antisocial personality disorder & $\mathrm{n} / \mathrm{a}$ & $1.17(0.16-8.67)$ & $1.68(0.40-7.03)$ \\
\hline Depressive personality disorder & $\mathrm{n} / \mathrm{a}$ & $8.68(2.55-29.54)$ & $6.00(1.79-20.11)$ \\
\hline Bipolar disorder (I/II) & $5.09(0.65-40.04)$ & $5.75(1.71-19.34)$ & $5.66(1.97-16.28)$ \\
\hline GAD & $3.92(0.50-30.72)$ & $6.14(2.11-17.87)$ & $5.31(2.05-13.78)$ \\
\hline Agoraphobia & $11.15(3.32-37.43)$ & $3.06(1.06-8.80)$ & $4.65(2.14-10.12)$ \\
\hline Specific phobia & $5.34(1.72-16.61)$ & $3.07(1.50-6.27)$ & $3.36(1.85-6.09)$ \\
\hline Social phobia & $4.74(1.50-14.98)$ & $8.15(4.08-16.29)$ & $6.52(3.65-11.64)$ \\
\hline Panic disorder & $4.24(0.92-19.49)$ & $2.94(1.02-8.47)$ & $3.15(1.32-7.52)$ \\
\hline Separation anxiety disorder & $1.72(0.22-13.51)$ & $3.90(1.59-9.56)$ & $3.16(1.39-7.15)$ \\
\hline Overanxious disorder & $5.21(1.37-19.77)$ & $1.38(0.42-4.56)$ & $2.09(0.88-4.98)$ \\
\hline ADHD & $3.46(0.44-27.04)$ & $5.39(1.86-15.64)$ & $4.66(1.80-12.04)$ \\
\hline Conduct disorder & $\mathrm{n} / \mathrm{a}$ & $1.03(0.14-7.59)$ & $0.71(0.10-5.21)$ \\
\hline Oppositional defiant disorder & $10.26(2.18-48.28)$ & $2.96(0.70-12.59)$ & $4.47(1.56-12.79)$ \\
\hline PTSD & $3.80(0.83-17.47)$ & $4.30(1.75-10.54)$ & $4.00(1.84-8.68)$ \\
\hline Anorexia nervosa & $13.29(1.65-106.87)$ & $4.54(0.60-34.55)$ & $6.71(1.54-29.23)$ \\
\hline Bulimia & $6.10(0.77-48.12)$ & 12.89 (4.78-34.75) & $10.74(4.36-26.47)$ \\
\hline Alcohol abuse & $0.87(0.11-6.78)$ & $0.62(0.15-2.59)$ & $0.65(0.20-2.11)$ \\
\hline Alcohol dependence & $\mathrm{n} / \mathrm{a}$ & $2.69(0.93-7.73)$ & $1.81(0.64-5.11)$ \\
\hline Substance abuse & $\mathrm{n} / \mathrm{a}$ & $0.61(0.08-4.45)$ & $0.42(0.06-3.04)$ \\
\hline Substance dependence & $\mathrm{n} / \mathrm{a}$ & $0.61(0.08-4.45)$ & $0.42(0.06-3.04)$ \\
\hline Marijuana abuse & $\mathrm{n} / \mathrm{a}$ & $0.68(0.09-4.97)$ & $0.47(0.06-3.39)$ \\
\hline Marijuana dependence & $\mathrm{n} / \mathrm{a}$ & $1.77(0.24-13.14)$ & $2.57(0.61-10.84)$ \\
\hline Smoking & $2.61(0.34-20.25)$ & $1.33(0.51-3.45)$ & $1.36(0.61-3.06)$ \\
\hline Psychosis & $1.82(0.10-32.28)$ & $9.58(4.02-22.83)$ & $0.65(0.20-2.11)$ \\
\hline Paranoia & $0.77(0.08-7.39)$ & $3.76(2.24-6.33)$ & $8.18(3.58-18.70)$ \\
\hline
\end{tabular}

Odds ratios, $95 \% \mathrm{CI}$; bold: $p<0.05$

$M D D$ major depressive disorder, $G A D$ generalized anxiety disorder, $A D H D$ attention-deficit hyperactivity disorder, $P T S D$ posttraumatic stress disorder, $n / a$ not available purging subtype exhibited higher impulsive traits than subjects with anorexia nervosa-restricting subtype, leading to the suggestion that this personality trait may reflect a shared underlying vulnerability for the comorbidity between OCD and eating disorders [4].

Impulsivity and compulsivity have been conceptualized as two opposite ends of a dimension [69]. In fact, diagnoses/syndromes associated with high impulsivity (such as ADHD) and mixed compulsive-impulsive diagnoses (such as the Gilles de la Tourette syndrome [69]) were linked to the MOCS, and not to the PCS, in our data. Hence, the inverse relation between impulsivity and compulsivity may be reflected by our two distinct OCD subtypes. Taking into account that hyperactivity/impulsivity symptoms were shown to be predictive for substance problems [21, 36], the lower association of alcohol abuse/illicit drug abuse with the PCS versus the significantly higher association with the MOCS (Zurich Study) may further confirm our hypothesis. However, substance abuse was no longer associated with any OCD subtype in the analyses of pooled data, which is in line with other studies showing a general lack of associations between OCD and substance use $[7,44]$. These inconclusive findings are possibly related to the conceptualization of the construct of impulsivity. Dalley et al. [18] reviewed the literature from both animal and human studies and characterized the multifaceted nature of impulsivity. The authors predicted that this construct would be fractioned into several types, involving various forms of disrupted top-down cognitive control that may coexist in the same subject. An open question, however, remains regarding the specific conditions that lead from impulsive syndromes to compulsive behavior [18]. 
Table 10 Pooled analysis combining the data of the Zurich Study, ZInEP, and PsyCoLaus for a selection of comparative comorbidities

\begin{tabular}{|c|c|c|c|c|c|c|}
\hline & \multicolumn{3}{|l|}{ Logistic regressions } & \multicolumn{3}{|c|}{ Multilevel analysis with random intercept } \\
\hline & \multicolumn{3}{|l|}{ Distinctive subtyping } & \multicolumn{3}{|c|}{ Distinctive subtyping } \\
\hline & Pure compulsions & $\begin{array}{l}\text { Mixed obsessive- } \\
\text { compulsive }\end{array}$ & Overall OCD & Pure compulsions & $\begin{array}{l}\text { Mixed obsessive- } \\
\text { compulsive }\end{array}$ & Overall OCD \\
\hline Sex & $1.02(0.48-2.18)$ & $1.39(0.80-2.42)$ & $1.23(0.79-1.93)$ & $0.95(0.36-2.52)$ & $1.43(1.10-1.84)$ & $1.24(0.79-1.93)$ \\
\hline MDD & $1.04(0.44-2.46)$ & $1.18(0.68-2.04)$ & $1.14(0.71-1.82)$ & $1.61(0.89-2.93)$ & $1.97(1.60-2.42)$ & $1.89(1.55-2.32)$ \\
\hline Bipolar disorder (I/II) & $4.72(1.42-15.65)$ & $5.34(1.94-14.69)$ & $5.59(2.50-12.51)$ & $3.01(2.06-4.40)$ & $3.71(1.51-9.11)$ & $3.66(1.77-7.56)$ \\
\hline Dysthymia & $1.25(0.50-3.10)$ & $2.54(0.66-9.78)$ & $2.03(0.72-5.73)$ & $0.68(0.10-4.60)$ & $1.26(0.29-5.44)$ & $1.01(0.27-3.79)$ \\
\hline GAD & $3.52(1.31-9.47)$ & $4.41(2.15-9.06)$ & $4.24(2.33-7.74)$ & $2.15(1.51-3.07)$ & $3.46(1.35-8.86)$ & $2.96(1.77-4.93)$ \\
\hline Agoraphobia & $3.52(1.22-10.14)^{*}$ & $3.84(1.70-8.66)$ & $3.89(2.01-7.55)$ & $2.83(1.04-7.70)$ & $3.22(1.98-5.25)$ & $3.15(1.81-5.47)$ \\
\hline Specific phobia & $3.61(1.65-7.89)$ & $2.09(1.11-3.96)$ & $2.70(1.64-4.43)$ & $3.61(1.61-8.06)$ & $2.03(1.18-3.48)$ & $2.56(1.65-3.96)$ \\
\hline Social phobia & $2.31(0.94-5.67)$ & $4.28(2.34-7.83)$ & $3.54(2.13-5.88)$ & $2.46(1.79-3.38)$ & $4.73(3.03-7.39)$ & $3.95(2.95-5.29)$ \\
\hline Panic disorder & $0.68(0.26-1.81)$ & $3.24(1.37-7.65)$ & $2.16(1.02-4.60)$ & $0.98(0.21-4.64)$ & $2.80(1.87-4.18)$ & $2.09(1.35-3.25)$ \\
\hline Bulimia & $1.02(0.29-3.50)$ & $7.42(2.53-21.81)^{*}$ & $4.81(1.80-12.85)^{*}$ & $1.31(0.26-6.62)$ & $7.05(2.47-20.18)$ & $5.11(1.67-15.61)$ \\
\hline Alcohol dependence & $1.75(0.56-5.47)$ & $1.46(0.65-3.32)$ & $1.59(0.80-3.16)$ & $1.06(0.36-3.16)$ & $1.40(0.76-2.61)$ & $1.23(0.67-2.25)$ \\
\hline Substance dependence & $0.96(0.20-4.71)$ & $2.56(0.86-7.66)$ & $1.90(0.75-4.83)$ & $0.90(0.13-6.42)$ & $1.61(0.60-4.35)$ & $1.31(0.69-2.46)$ \\
\hline
\end{tabular}

$n=5811$, odds ratios, $95 \%$ confidence interval; bold: $p<0.05$

$M D D$ major depressive disorder, $G A D$ generalized anxiety disorder

* Significant Breslow-Day test for homogeneity of the odds ratios $(d f=2, p<0.05)$ indicating multilevel analysis to be superior

In sum, some authors [50] stated that the presence of compulsions is informative to distinguish this disorder from other anxiety disorders and depression. We have expanded this knowledge by demonstrating that compulsions exhibit a strikingly discriminant validity with regard to comorbid syndromes/disorders, if differentiated into a pure and mixed form.

\section{Limitations}

First, the main limitation of the present study due to the methodological differences between the epidemiological surveys must be underlined. In particular, the differences regarding the instruments and the sampling procedure between the PsyCoLaus sample and the two other samples are noteworthy. For example, the overall OCD prevalence was obviously lower in the PsyCoLaus sample. As demonstrated by a recent meta-analysis and meta-regression [63], the DIGS assessment is associated with lower OCD prevalence rates. Therefore, this discrepancy is probably a result of the instrument rather than explainable by factors such as regional differences between the PsyCoLaus sample and the Zurich Study and ZInEP sample, respectively. In contrast, the Zurich Study and the ZInEP study were parallelized with regard to basic methodological features (for more details see Ajdacic-Gross et al. [2]) and showed more similarities. Second, while the basic findings distinguishing between PCS and the MOCS were consistent, the more detailed results depicted a relatively high degree of heterogeneity across the studies. There are two apparent reasons for this disparity: (a) the longitudinal Zurich Study included more cases, and in particular more pure compulsive cases in their twenties-cases which otherwise might get lost in retrospective interviews. An immediate consequence of this discrepancy is the distinctly lower age at onset of first symptoms in the Zurich Study. (b) The instruments-DIGS (PsyCoLaus) and SPIKE (Zurich Study and ZInEP) - are constructed differently, in particular regarding the probing of the introductory part of each psychopathological section. Third, in contrast to the overall pattern, a few specific variables showed inconsistent patterns. Fourth, we cannot rule out the possibility that the PCS may subsume further symptom clusters found in previous research [38], partly constituting separate disorders in the DSM-5. Also the lack of differentiation between compulsions and tics might have neglected meaningful subgroups of persons. Due to the restriction of the SPIKE and DIGS obsession screening question to "thoughts" and "images," we cannot ascertain whether the compulsive symptoms were unaccompanied by impulses or sensory phenomena. Sensory phenomena, e.g., localized tactile and musculoskeletal sensations, "just-right" feelings, feelings of incompleteness, energy, and an urge, are substantially more frequent than expected and occur more often in males and OCD subjects with an early age of onset [47] — both characteristics applying to subjects with PCS. Hence, this subtype needs to be replicated, differentiated, and further validated with regard to sensory phenomena/obsessions other than 
thoughts and images in future studies. Fifth, the number of cases was small for some diagnoses. Sixth, due to aspects such as reporting bias, there was a risk for misclassification. Finally, the distinction into the PCS and the MOCS may reflect different severity levels leading to more complex - and accordingly more comorbid—cases.

Despite these limitations, our comparative study including three population-based samples underlined the stable characterization by psychosocial risk factors and comorbid profiles of two basic OCD subtypes. These two subtypes were characterized by specific psychosocial impairment and a large number of comorbid syndromes/ diagnoses, possibly indicating differing pathophysiological mechanisms. While pure compulsions were distinguishable by virtually no risk factors associations, the MOCS was characterized by a large number of associations suggesting putative nature-nurture interactions between familial predisposition and childhood adversities. We speculate that biological mechanisms of different range and overlap underlie this differing phenotypic OCD manifestation. Taking into account that some authors have called for a dimensional approach within OCD research $[7,8,29,39]$, our results need to be balanced in consideration of this approach in future studies. For example, our PCS conceivably depicts an extreme variant with regard to symptom dimensions, with maximal loads on one (or more) dimensions versus minimal loading on one (or more) dimensions. In addition, only subjects with an OCD diagnosis were selected in the current analyses. While $2-3.5 \%$ of the general population meet the diagnostic criteria for an OCD disorder, a much larger proportion of subjects $(8.7-25 \%)$ manifest obsessions and/ or compulsions at the symptom level [7,26], albeit with a high chance of eventual remission [23]. For example, a common phenomenon at subthreshold level is the performance of rituals providing a sense of security. Therefore, further studies should examine whether the distinct subtype approach also leads to valid subtypes within subjects with subsyndromal OCD.

\begin{abstract}
Acknowledgments We thank all the participants who participated in the epidemiological surveys as well as all the interviewers who collected the data. The Zurich Study was supported by the Swiss National Science Foundation (Grant No. 32-50881.97). ZInEP was supported by a private donation. The donor had no further role in experimental design, collection, analysis and interpretation of data, the writing of this report, or the decision to submit this paper for publication. The PsyCoLaus study was and is supported by research grants from GlaxoSmithKline, the Faculty of Biology and Medicine of Lausanne, and the Swiss National Science Foundation (Grants 3200B0-105993, 3200B0-118308, 33CSCO-122661, 33CS30139468, and 33CS30-148401).
\end{abstract}

Conflict of interest On behalf of all authors, the corresponding author states that there is no conflict of interest.

\section{References}

1. Abramowitz JS, Franklin ME, Schwartz SA, Furr JM (2003) Symptom presentation and outcome of cognitive-behavioral therapy for obsessive-compulsive disorder. J Consult Clin Psychol 71:1049-1057

2. Ajdacic-Gross V, Muller M, Rodgers S, Warnke I, Hengartner MP, Landolt K, Hagenmuller F, Meier M, Tse LT, Aleksandrowicz A, Passardi M, Knopfli D, Schonfelder H, Eisele J, Rusch N, Haker H, Kawohl W, Rossler W (2014) The ZInEP Epidemiology Survey: background, design and methods. Int J Methods Psychiatr Res 23:451-468

3. Ajdacic-Gross V, Rodgers S, Müller M, Hengartner MP, Aleksandrowicz A, Kawohl W, Heekeren K, Rössler W, Angst J, Castelao E, Vandeleur C, Preisig M (2014) Pure subtypes make a big difference. Distinctive versus fuzzy subtyping in specific phobias(submitted)

4. Altman SE, Shankman SA (2009) What is the association between obsessive-compulsive disorder and eating disorders? Clin Psychol Rev 29:638-646

5. Angst J, Azorin JM, Bowden CL, Perugi G, Vieta E, Gamma A, Young AH (2011) Prevalence and characteristics of undiagnosed bipolar disorders in patients with a major depressive episode: the BRIDGE study. Arch Gen Psychiatry 68:791-798

6. Angst J, Dobler-Mikola A, Binder J (1984) The Zurich studya prospective epidemiological study of depressive, neurotic and psychosomatic syndromes. I. Problem, methodology. Eur Arch Psychiatry Neurol Sci 234:13-20

7. Angst J, Gamma A, Endrass J, Goodwin R, Ajdacic V, Eich D, Rossler W (2004) Obsessive-compulsive severity spectrum in the community: prevalence, comorbidity, and course. Eur Arch Psychiatry Clin Neurosci 254:156-164

8. Angst J, Gamma A, Endrass J, Hantouche E, Goodwin R, Ajdacic V, Eich D, Rossler W (2005) Obsessive-compulsive syndromes and disorders: significance of comorbidity with bipolar and anxiety syndromes. Eur Arch Psychiatry Clin Neurosci 255:65-71

9. Angst J, Gamma A, Neuenschwander M, Ajdacic-Gross V, Eich D, Rössler W, Merikangas KR (2005) Prevalence of mental disorders in the Zurich cohort study: a twenty year prospective study. Epidemiol Psichiatr Soc 14:68-76

10. Berney A, Preisig M, Matthey ML, Ferrero F, Fenton BT (2002) diagnostic interview for genetic studies (DIGS): inter-rater and test-retest reliability of alcohol and drug diagnosis. Drug Alcohol Depend 65:149-158

11. Bernstein DP, Ahluvalia T, Pogge D, Handelsman L (1997) Validity of the Childhood Trauma Questionnaire in an adolescent psychiatric population. J Am Acad Child Adolesc Psychiatry 36:340-348

12. Bernstein DP, Fink L (1998) Childhood Trauma Questionnaire: a retrospective self-report. Psychological Corporation, San Antonio

13. Bernstein DP, Stein JA, Newcomb MD, Walker E, Pogge D, Ahluvalia T, Stokes J, Handelsman L, Medrano M, Desmond D, Zule W (2003) Development and validation of a brief screening version of the Childhood Trauma Questionnaire. Child Abuse Negl 27:169-190

14. Bloch MH, Landeros-Weisenberger A, Rosario MC, Pittenger C, Leckman JF (2008) Meta-analysis of the symptom structure of obsessive-compulsive disorder. Am J Psychiatry 165:1532-1542

15. Breslau N, Peterson EL, Kessler RC, Schultz LR (1999) Short screening scale for DSM-IV posttraumatic stress disorder. Am J Psychiatry 156:908-911

16. Carter AS, Pollock RA (2000) Obsessive compulsive disorder in childhood. Curr Opin Pediatr 12:325-330 
17. Chabane N, Delorme R (2007) Obsessive-compulsive disorder in children and adolescents. Rev Prat 57:45-51

18. Dalley JW, Everitt BJ, Robbins TW (2011) Impulsivity, compulsivity, and top-down cognitive control. Neuron 69:680-694

19. Delucchi KL, Katerberg H, Stewart SE, Denys DA, Lochner C, Stack DE, den Boer JA, van Balkom AJ, Jenike MA, Stein DJ, Cath DC, Mathews CA (2011) Latent class analysis of the YaleBrown Obsessive-Compulsive Scale symptoms in obsessivecompulsive disorder. Compr Psychiatry 52:334-341

20. Derogatis RL (1977) Symptom Checklist 90, R-version manual I: scoring, administration, and procedures for the SCL-90. Johns Hopkins Press, Baltimore

21. Elkins IJ, McGue M, Iacono WG (2007) Prospective effects of attention-deficit/hyperactivity disorder, conduct disorder, and sex on adolescent substance use and abuse. Arch Gen Psychiatry 64:1145-1152

22. Falret JP (1866) Discussion sur la folie raisonnante. Ann Med Psychol 24:382-426

23. Fineberg NA, Hengartner MP, Bergbaum C, Gale T, Rossler W, Angst J (2013) Remission of obsessive-compulsive disorders and syndromes; evidence from a prospective community cohort study over 30 years. Int J Psychiatry Clin Pract 17:179-187

24. Fineberg NA, Hengartner MP, Bergbaum CE, Gale TM, Gamma A, Ajdacic-Gross V, Rossler W, Angst J (2013) A prospective population-based cohort study of the prevalence, incidence and impact of obsessive-compulsive symptomatology. Int J Psychiatry Clin Pract 17:170-178

25. Firmann M, Mayor V, Vidal PM, Bochud M, Pecoud A, Hayoz D, Paccaud F, Preisig M, Song KS, Yuan X, Danoff TM, Stirnadel HA, Waterworth D, Mooser V, Waeber G, Vollenweider P (2008) The CoLaus study: a population-based study to investigate the epidemiology and genetic determinants of cardiovascular risk factors and metabolic syndrome. BMC Cardiovasc Disord 8:6

26. Fullana MA, Mataix-Cols D, Caspi A, Harrington H, Grisham JR, Moffitt TE, Poulton R (2009) Obsessions and compulsions in the community: prevalence, interference, help-seeking, developmental stability, and co-occurring psychiatric conditions. Am J Psychiatry 166:329-336

27. Gillan CM, Sahakian BJ (2015) Which is the driver, the obsessions or the compulsions, in OCD? Neuropsychopharmacology 40:247-248

28. Grabe HJ, Meyer C, Hapke U, Rumpf HJ, Freyberger HJ, Dilling H, John U (2001) Lifetime-comorbidity of obsessive-compulsive disorder and subclinical obsessive-compulsive disorder in Northern Germany. Eur Arch Psychiatry Clin Neurosci 251:130-135

29. Grisham JR, Fullana MA, Mataix-Cols D, Moffitt TE, Caspi A, Poulton R (2011) Risk factors prospectively associated with adult obsessive-compulsive symptom dimensions and obsessive-compulsive disorder. Psychol Med 41:2495-2506

30. Hantouche EG, Lancrenon S (1996) Modern typology of symptoms and obsessive-compulsive syndromes: results of a large French study of 615 patients. L'Encéphale 22 Spec No 1:9-21

31. Hardt J, Egle UT, Kappis B, Hessel A, Brahler E (2004) Symptom checklist SCL-27. Psychother Psychosom Med Psychol 54:214-223

32. Helbing ML, Ficca M (2009) Obsessive-compulsive disorder in school-age children. J Sch Nurs 25:15-26

33. Hochstrasser B, Angst J (1996) The Zurich study: XXII. Epidemiology of gastrointestinal complaints and comorbidity with anxiety and depression. Eur Arch Psychiatry Clin Neurosci 246:261-272

34. Katerberg H, Delucchi KL, Stewart SE, Lochner C, Denys DA, Stack DE, Andresen JM, Grant JE, Kim SW, Williams KA, den Boer JA, van Balkom AJ, Smit JH, van Oppen P, Polman A,
Jenike MA, Stein DJ, Mathews CA, Cath DC (2010) Symptom dimensions in OCD: item-level factor analysis and heritability estimates. Behav Genet 40:505-517

35. Kendell RE (1974) The stability of psychiatric diagnoses. Br J Psychiatry 124:352-356

36. Lee SS, Hinshaw SP (2006) Predictors of adolescent functioning in girls with attention deficit hyperactivity disorder (ADHD): the role of childhood ADHD, conduct problems, and peer status. J Clin Child Adolesc Psychol 35:356-368

37. Lochner C, Stein DJ (2001) Gender in obsessive-compulsive disorder and obsessive-compulsive spectrum disorders. Arch Womens Ment Health 4:19-26

38. Mataix-Cols D (2006) Deconstructing obsessive-compulsive disorder: a multidimensional perspective. Curr Opin Psychiatry 19:84-89

39. Mataix-Cols D, Rosario-Campos MC, Leckman JF (2005) A multidimensional model of obsessive-compulsive disorder. Am J Psychiatry 162:228-238

40. McKay D, Abramowitz JS, Calamari JE, Kyrios M, Radomsky A, Sookman D, Taylor S, Wilhelm S (2004) A critical evaluation of obsessive-compulsive disorder subtypes: symptoms versus mechanisms. Clin Psychol Rev 24:283-313

41. Merikangas KR, Zhang H, Avenevoli S, Acharyya S, Neuenschwander M, Angst J (2003) Longitudinal trajectories of depression and anxiety in a prospective community study: the Zurich Cohort Study. Arch Gen Psychiatry 60:993-1000

42. Miguel EC, Leckman JF, Rauch S, do Rosario-Campos MC, Hounie AG, Mercadante MT, Chacon P, Pauls DL (2005) Obsessive-compulsive disorder phenotypes: implications for genetic studies. Mol Psychiatry 10:258-275

43. Muthén LK, Muthén BO (1998-2012) Mplus User's Guide. 7th edn. In: Muthén \& Muthén, Los Angeles, CA

44. Nestadt G, Samuels J, Riddle MA, Liang KY, Bienvenu OJ, Hoehn-Saric R, Grados M, Cullen B (2001) The relationship between obsessive-compulsive disorder and anxiety and affective disorders: results from the Johns Hopkins OCD Family Study. Psychol Med 31:481-487

45. Novy J, Castelao E, Preisig M, Vidal PM, Waeber G, Vollenweider P, Rossetti AO (2012) Psychiatric co-morbidities and cardiovascular risk factors in people with lifetime history of epilepsy of an urban community. Clin Neurol Neurosurg 114:26-30

46. Nurnberger JI Jr, Blehar MC, Kaufmann CA, York-Cooler C, Simpson SG, Harkavy-Friedman J, Severe JB, Malaspina D, Reich T (1994) Diagnostic interview for genetic studies. Rationale, unique features, and training. NIMH genetics initiative. Arch Gen Psychiatry 51:849-859 discussion 863-844

47. Prado HS, Rosario MC, Lee J, Hounie AG, Shavitt RG, Miguel EC (2008) Sensory phenomena in obsessive-compulsive disorder and tic disorders: a review of the literature. CNS Spectr 13:425-432

48. Preisig M, Fenton BT, Matthey ML, Berney A, Ferrero F (1999) Diagnostic interview for genetic studies (DIGS): inter-rater and test-retest reliability of the French version. Eur Arch Psychiatry Clin Neurosci 249:174-179

49. Preisig M, Waeber G, Vollenweider P, Bovet P, Rothen S, Vandeleur C, Guex P, Middleton L, Waterworth D, Mooser V, Tozzi F, Muglia P (2009) The PsyCoLaus study: methodology and characteristics of the sample of a population-based survey on psychiatric disorders and their association with genetic and cardiovascular risk factors. BMC Psychiatry 9:9

50. Rasmussen SA, Eisen JL (1994) The epidemiology and differential diagnosis of obsessive compulsive disorder. J Clin Psychiatry 55(Suppl):5-10 discussion 11-14

51. Ravizza L, Maina G, Bogetto F (1997) Episodic and chronic obsessive-compulsive disorder. Depress Anxiety 6:154-158

52. Retz-Junginger P, Retz W, Blocher D, Stieglitz RD, Georg T, Supprian T, Wender PH, Rosler M (2003) Reliability and validity 
of the Wender-Utah-Rating-Scale short form. Retrospective assessment of symptoms for attention deficit/hyperactivity disorder. Nervenarzt 74:987-993

53. Retz-Junginger P, Retz W, Blocher D, Weijers HG, Trott GE, Wender PH, Rossler M (2002) Wender Utah Rating Scale. The short-version for the assessment of the attention-deficit hyperactivity disorder in adults. Nervenarzt 73:830-838

54. Retz-Junginger P, Retz W, Schneider M, Schwitzgebel P, Steinbach E, Hengesch G, Rosler M (2007) Gender differences in self-descriptions of child psychopathology in attention deficit hyperactivity disorder. Nervenarzt 78:1046-1051

55. Rosler M, Retz W, Retz-Junginger P, Thome J, Supprian T, Nissen T, Stieglitz RD, Blocher D, Hengesch G, Trott GE (2004) Tools for the diagnosis of attention-deficit/hyperactivity disorder in adults. Self-rating behaviour questionnaire and diagnostic checklist. Nervenarzt 75:888-895

56. Rosler M, Retz W, Retz-Junginger P, Hengesch G, Schneider M, Supprian T et al (2004) Prevalence of attention deficit-/hyperactivity disorder (ADHD) and comorbid disorders in young male prison inmates. Eur Arch Psychiatry Clin Neurosci 254:365-371

57. Rossler W, Ajdacic-Gross V, Haker H, Rodgers S, Muller M, Hengartner MP (2015) Subclinical psychosis syndromes in the general population: results from a large-scale epidemiological survey among residents of the canton of Zurich, Switzerland. Epidemiol Psychiatr Sci 24:69-77

58. Rossler W, Hengartner MP, Ajdacic-Gross V, Haker H, Angst J (2014) Impact of childhood adversity on the onset and course of subclinical psychosis symptoms-results from a 30-year prospective community study. Schizophr Res 153:189-195

59. Rossler W, Riecher-Rossler A, Angst J, Murray R, Gamma A, Eich D, van Os J, Gross VA (2007) Psychotic experiences in the general population: a twenty-year prospective community study. Schizophr Res 92:1-14

60. Rossler W, Vetter S, Muller M, Gallo WT, Haker H, Kawohl W, Lupi G, Ajdacic-Gross V (2011) Risk factors at the low end of the psychosis continuum: much the same as at the upper end? Psychiatry Res 189:77-81

61. Steketee G, Chambless DL, Tran GQ (2001) Effects of axis I and II comorbidity on behavior therapy outcome for obsessive-compulsive disorder and agoraphobia. Compr Psychiatry 42:76-86

62. Sturm R (2009) Obsessive-compulsive disorder in children: the role of nurse practitioners. J Am Acad Nurse Pract 21:393-401

63. Swets M, Dekker J, van Emmerik-van Oortmerssen K, Smid GE, Smit F, de Haan L, Schoevers RA (2014) The obsessive compulsive spectrum in schizophrenia, a meta-analysis and meta-regression exploring prevalence rates. Schizophr Res 152:458-468

64. Taylor S (2011) Early versus late onset obsessive-compulsive disorder: evidence for distinct subtypes. Clin Psychol Rev 31:1083-1100

65. Toro J, Cervera M, Osejo E, Salamero M (1992) Obsessive-compulsive disorder in childhood and adolescence: a clinical study. $\mathbf{J}$ Child Psychol Psychiatry 33:1025-1037

66. Tukel R, Polat A, Ozdemir O, Aksut D, Turksoy N (2002) Comorbid conditions in obsessive-compulsive disorder. Compr Psychiatry 43:204-209

67. Visser HA, van Oppen P, van Megen HJ, Eikelenboom M, van Balkom AJ (2014) Obsessive-compulsive disorder; chronic versus non-chronic symptoms. J Affect Disord 152-154:169-174

68. Williams MT, Farris SG, Turkheimer E, Pinto A, Ozanick K, Franklin ME, Liebowitz M, Simpson HB, Foa EB (2011) Myth of the pure obsessional type in obsessive-compulsive disorder. Depress Anxiety 28:495-500

69. Wright A, Rickards H, Cavanna AE (2012) Impulse-control disorders in Gilles de la Tourette syndrome. J Neuropsychiatry Clin Neurosci 24:16-27

70. Wulff H (2006) Childhood trauma questionnaire. Entwicklung einer deutschsprachigen version und überprüfung bei psychiatrisch-psychotherapeutisch behandelten patienten. Universität Lübeck, Lübeck 